\section{Acknowledgments.}

Financial support. No financial support was provided relevant to this article.

Conflicts of interest. All authors report no conflict of interest relevant to this article.

\section{References}

1. European Antimicrobial Resistance Surveillance Network (EARS-Net). European Centre for Disease Prevention and Control website. http://
ecdc.europa.eu/en/activities/surveillance/EARS-Net/Pages/index.aspx. Published 2018.

2. Weber DJ, Rutala WA, Schaffner W. Lesson learned: protection of healthcare workers from infectious disease risks. Crit Care Med 2010;38:S306S314.

3. Radonovich LJ Jr, Simberkoff MS, Bessesen MT, et al. N95 respirators vs medical masks for preventing influenza among health care personnel: a randomized clinical trial. JAMA 2019;322:824-833.

4. Sherertz RJ, Reagan DR, Hampton KD, et al. A cloud adult: the Staphylococcus aureus virus interaction revised. Ann Intern Med 1996;124:539-547.

\title{
Reduction in ambulatory visits for acute, uncomplicated bronchitis: an unintended but welcome result of the coronavirus disease 2019 (COVID-19) pandemic
}

\author{
Thomas J. Dilworth PharmD (1) and Charles F. Brummitt MD \\ AdvocateAuroraHealth, Milwaukee, Wisconsin
}

To the Editor-The coronavirus disease 2019 (COVID-19) pandemic has adversely impacted nearly all aspects of life since emerging in late 2019. Notably, surges in COVID-19 cases have led to antibiotic overprescribing in the inpatient setting, hampering ongoing antimicrobial stewardship efforts. ${ }^{1,2}$ However, patients' reluctance to seek healthcare during the pandemic, particularly for minor ailments, may lead to unexpected outpatient antimicrobial stewardship gains. Jeffery et $\mathrm{al}^{3}$ reported an inverse relationship between COVID-19 cases and daily counts of emergency department visits in 5 US states between January and April of 2020. Diagnoses were not reported in this study, and the authors concluded that clinicians should reinforce to patients the importance of seeking emergency department care for serious conditions. We have previously reported the results of a systemwide initiative to reduce antibiotic prescribing for ambulatory adults with acute, uncomplicated bronchitis. ${ }^{4}$ Internally, we continue to track and report these data. Recently, we observed a profound reduction in both the overall number of patients seen and discharged with a primary diagnosis of bronchitis and the number of antibiotic prescriptions written for these encounters (Fig. 1). In addition to patients' not seeking care due to the pandemic, there are a number of other, possible explanations for our observed decline in visits. Stay-at-home orders and social distancing appear to have reduced the burden of common respiratory viruses in the community, leading to fewer cases of acute, uncomplicated bronchitis, ${ }^{5,6}$ for which the primary etiology is viral. ${ }^{7}$ Patients may increasingly seek care outside of our health system during the pandemic. The pandemic has also shifted patient care to telemedicine. To assess this phenomenon, we captured whether or not a visit was a telemedicine encounter and then analyzed the recent ambulatory clinic data. Of the 394 ambulatory clinic bronchitis visits during July and August, $112(28.4 \%)$ were telemedicine encounters, a higher proportion of

Author for correspondence: Thomas J. Dilworth, E-mail: thomas.dilworth@aah.org Cite this article: Dilworth TJ and Brummitt CF. (2021). Reduction in ambulatory visits for acute, uncomplicated bronchitis: an unintended but welcome result of the coronavirus disease 2019 (COVID-19) pandemic. Infection Control \& Hospital Epidemiology, 42: 1291-1292, https://doi.org/10.1017/ice.2020.1233 total visits than observed in previous months. Thus, a shift toward more telemedicine visits was revealed in our data set.

The COVID-19 pandemic, while challenging for so many other aspects of antimicrobial stewardship, has led to an overall net
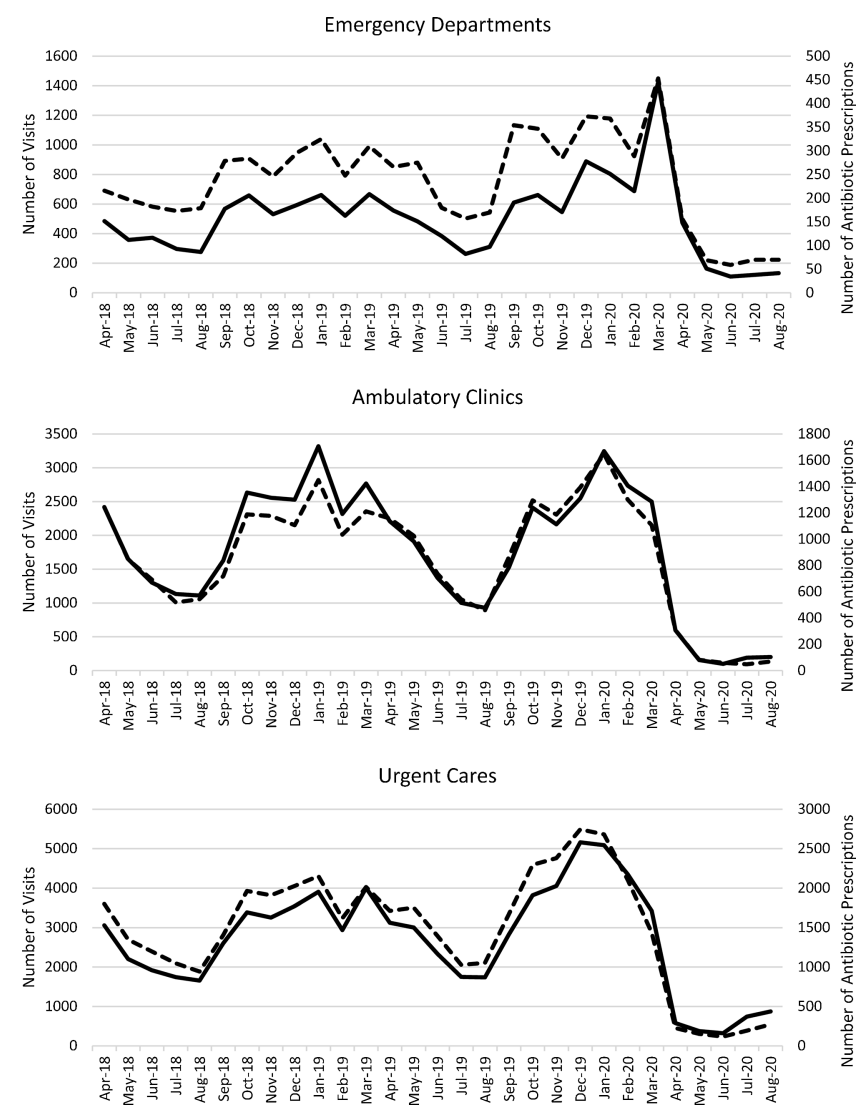

Fig. 1. Number of ambulatory patients with a primary diagnosis of bronchitis, April 2017-August 2020. Complete lines, number of visits; dashed lines, number of antibiotic prescriptions. 
reduction in ambulatory adults seeking care for bronchitis in our health system and to a dramatic reduction in antibiotic prescribing for that condition. Reducing unnecessary, outpatient antibiotic prescribing has long been a difficult challenge for many antimicrobial stewardship programs. Our challenge will be to educate patients and clinicians to maintain these improvements in outpatient, acute bronchitis management as the pandemic is brought under control and outpatient visits return to prepandemic levels.

\section{References}

1. Abelenda-Alonso G, Padullés A, Rombauts A, et al. Antibiotic prescription during the COVID-19 pandemic: a biphasic pattern. Infect Control Hosp Epidemiol 2020. doi: 10.1017/ice.2020.381.

2. Nestler M, Godbout E, Lee K, et al. Impact of COVID-19 on pneumoniafocused antibiotic use at an academic medical center. Infect Control Hosp Epidemiol 2020. doi: 10.1017/ice.2020.362.

3. Jeffery MM, D'Onofrio G, Paek $\mathrm{H}$, et al. Trends in emergency department visits and hospital admissions in health care systems in 5 states in the first months of the COVID-19 pandemic in the US. JAMA Intern Med 2020 Aug 3 [Epub ahead of print]. doi: 10.1001/jamainternmed.2020. 3288.

4. Pagels CM, Dilworth TJ, Fehrenbacher L, Singh M, Brummitt CF. Impact of an electronic best-practice advisory in combination with prescriber education on antibiotic prescribing for ambulatory adults with acute, uncomplicated bronchitis within a large integrated health system. Infect Control Hosp Epidemiol 2019;40:1348-1355.

5. Nolen LD, Seeman S, Bruden D, et al. Impact of social distancing and travel restrictions on non-COVID-19 respiratory hospital admissions in young children in rural Alaska. Clin Infect Dis 2020 [Epub ahead of print]. doi: 10.1093/cid/ciaal328peds.

6. Hatoun J, Correa ET, Donahue SMA, Vernacchio L. Social Distancing for COVID-19 and Diagnoses of Other Infectious Diseases in Children Pediatrics. 2020 Sep 2 [Epub ahead of print]. doi: 10.1542/peds. 2020-006460.

7. Harris AM, Hicks LA, Qaseem A. Appropriate antibiotic use for acute respiratory tract infection in adults. Ann Intern Med 2016;165:674.

\title{
Implementation of COVID-19 Provider Resource Task Force: A provider support initiative during emergency preparedness in a quaternary-care center in western Michigan
}

\author{
Vetriselvi Moorthy $\mathrm{MD}^{1}$ (1), Mudita Bhugra $\mathrm{MD}^{1}$, Curtis J. Behenna $\mathrm{DO}^{1}$, Manivannan Veerasamy $\mathrm{MD}^{2}$, \\ Michael J. Harrison $\mathrm{MD}^{3}$, Liam R. Sullivan $\mathrm{DO}^{1}$, Russell J. Lampen $\mathrm{DO}^{1}$, Habiba Hassouna $\mathrm{MD}^{1}$ \\ and Jorgelina T. de Sanctis MD ${ }^{1}$ \\ ${ }^{1}$ Spectrum Health Infectious Diseases/Michigan State University, Grand Rapids, Michigan, ${ }^{2}$ Spectrum Health Richard McNamara Cardiovascular Diseases \\ Fellowship/Michigan State University, Grand Rapids, Michigan and ${ }^{3}$ Specialties/Digestive Health, Spectrum Health Medical Group, Grand Rapids, Michigan
}

To the Editor-On March 11, 2020, World Health Organization (WHO) announced coronavirus disease 2019 (COVID-19) a pandemic. ${ }^{1}$ Spectrum Health System, like many other healthcare systems, activated an emergency preparedness command center and implemented strategies to mitigate the impact of COVID-19. Spectrum Health System is a nonprofit quaternary-care health system based in Grand Rapids, Michigan. More than 4,600 physicians and advanced-practice providers offer care to patients through 14 hospitals, including Helen DeVos Children's Hospital and 150 ambulatory clinics. Grand Rapids medical community also includes 2 other health systems, many ambulatory specialty and subspecialty practices, and rehabilitation units. During the COVID-19 pandemic, Spectrum Health initiated a work group as a support initiative for the patient-facing clinicians in the entire community.

\section{Methods}

The COVID-19 Provider Resource Work Group and hotline were commissioned on March 19, 2020. The aims of the work group

Author for correspondence: Vetriselvi Moorthy, 230 Michigan St NE, Grand Rapids, Michigan 49503. E-mail: Vetriselvi.moorthy@spectrumhealth.org

Cite this article: Moorthy V, et al. (2021). Implementation of COVID-19 Provider Resource Task Force: A provider support initiative during emergency preparedness in a quaternary-care center in western Michigan. Infection Control \& Hospital Epidemiology, 42: 1292-1294, https://doi.org/10.1017/ice.2020.1247 were (1) to provide real-time provider-to-provider education regarding questions that pertain to COVID-19; (2) to respond to a COVID-19 e-mail inbox that received questions from 31,000 employees within the Spectrum Health System; (3) to enable triage providers to direct their patients to appropriate channels; and (4) to improve provider access to updates on testing, treatment guidelines, and web-based resources. In total, 18 Spectrum Health physicians from infectious disease, allergy and immunology, internal medicine, and pulmonary critical care, as well as infectious disease fellow physicians volunteered to be part of the work group.

Initially, clinical questions from all the providers across the medical community would go through the provider hotline. This hotline was attended by a nurse who directed the appropriate calls to the on-call physician from the work group. Physicians self-assigned themselves to 4-hour shifts 7 days a week from 8 A.M. to 9 P.M. on a secure HIPAA-compliant communication platform called Perfect Serve. A shared inbox "covid19dr" was attached to the physicians' personal organization e-mail to receive questions. After an initial meeting that was organized to review the goals and objectives, the work group communicated daily to discuss the challenges, work flow, and current literature. Physicians self-educated on the current literature by reviewing Spectrum Health LitCovid, an internally created database maintained by

(c) The Author(s) 2020. This is an Open Access article, distributed under the terms of the Creative Commons Attribution licence (http://creativecommons.org/licenses/by/4.0/), which permits unrestricted re-use, distribution, and reproduction in any medium, provided the original work is properly cited. 